\title{
Utilization of over-the-counter analgesics in two private medical insurance schemes in South Africa
}

This article was published in the following Dove Press journal:

Drug, Healthcare and Patient Safety

\author{
Neelaveni Padayachee (D) \\ Alan D Rothberg $\mathbb{D}^{2}$ \\ Ilse Truter iD $^{3}$ \\ Neil Butkow (iD) \\ 'Department of Pharmacy and \\ Pharmacology, Faculty of Health Sciences, \\ University of Witwatersrand, \\ Johannesburg, Gauteng, South Africa; \\ ${ }^{2}$ School of Therapeutic Sciences, Faculty \\ of Health Sciences, University of \\ Witwatersrand, Johannesburg, Gauteng, \\ South Africa; ${ }^{3}$ Department of Pharmacy, \\ Nelson Mandela University, Port \\ Elizabeth, South Africa
}

\begin{abstract}
Introduction: In South Africa there is an easy access to over-the-counter (OTC) medicines and expenditure is high. Certain OTC products are available to the public in general stores, while others may only be available at pharmacies. It is also common for OTC medicines to be prescribed by a doctor for treatment of minor illnesses. Individuals with medical insurance usually have cover for these products, but typically only to a limited extent.
\end{abstract}

Aim: To investigate the utilization patterns in two medical insurance schemes of OTC analgesic products in the Anatomical Therapeutic Chemical (ATC) category N02BE51 which includes medicines containing paracetamol and varying combinations of codeine, caffeine and antihistamines.

Methodology: Data were obtained for two benefit plans, one with generous, high benefits (HI), the other with lower benefits (LO). Data covered utilization of OTC medicines in the N02BE51 group, indicating whether the medicines were purchased at a pharmacy or dispensed by a doctor. Doctors were further categorised as contracted/network or nonnetwork providers. Product costs and volumes were analysed according to access directly by the beneficiary, recommendation by a pharmacist, or prescription from a doctor.

Results: Compared to doctors, pharmacists issued more-expensive products. Average costs were higher in the HI plan compared to the LO plan. Pharmacists showed a preference for dispensing larger and more expensive pack sizes. Doctors showed better cost containment: the average cost of products in HI was twice that of LO. Doctors dispensing directly to patients issued smaller pack sizes and lower-priced products. Contracted network doctors did not appear to impact on costs.

Conclusion: Among the privately-insured individuals studied, the availability, cost and formulation of N02BE51 OTC products appeared to be poorly regulated, whether by the consumer, pharmacist, medical insurance scheme or legislation. Doctors demonstrate better cost containment by prescribing less costly, smaller pack-size alternatives compared to pharmacists.

Keywords: paracetamol, codeine, anti-histamines, pharmacists, doctors, cost, pack size

\section{Introduction}

By definition, "ethical medicines" are medicines that can only be accessed by patients on a doctor's prescription. Over-the-counter (OTC) medicines are not subject to such control and, being more available, contribute significantly to South Africa's annual healthcare expenditure. According to reliable industry information, in 2015 R39.5bn was spent on all medicines ( $\mathrm{R}=$ South African Rand; in 2015 R12.6=1US Dollar). The OTC market accounted for almost $26 \%$ of the total amount (R10.2bn) ${ }^{1}$ One particular manufacturer featured as the leader in OTC sales, an achievement highlighted in the company's 2018 annual report which showed OTC market growth of $7.6 \%$ (calculated at R1.898bn). ${ }^{2}$
Correspondence: Neelaveni Padayachee Department of Pharmacy and Pharmacology, Faculty of Health Sciences, University of Witwatersrand, 7 York Road, Parktown, Johannesburg 2193, South Africa

Tel +27 II 7172269

Email neelaveni.padayachee@wits.ac.za 
The ease of access to OTC medicines by consumers has resulted in a perception that the products are harmless and do not pose health or other risks. ${ }^{3}$ These medicines, available without a prescription, are categorised by the national accreditation and registering body as Schedule 0,1 or 2 medicines. ${ }^{4}$ Schedule 0 medicines are available at general stores and supermarkets, while Schedule 1 and 2 medicines $(\mathrm{S} 1, \mathrm{~S} 2)$ are kept behind the counter at pharmacies but can still be purchased without a prescription. ${ }^{4}$ Many OTC products are "poly-pharmaceuticals" and contain mixtures of various Schedule 1-2 medicines, but the evidence base for their effectiveness is generally lacking. Most have "flown under the radar" in terms of safety with the exception of ephedrine, pseudoephedrine and codeine. In the latter cases the Medicines and Related Substances Act 101 of 1965 was amended to limit the milligram quantity of these substances in OTC preparations and restrict the number of packs that an individual is able to purchase. ${ }^{5-7}$ While placing the above restrictions on access to codeine, the legislation is less prescriptive about the poly-pharmaceutical formulations of OTC medicines. Freely available to the public via cash payments, OTC medicines are also available to medically-insured beneficiaries via their "medical aid schemes", whether accessed directly by the beneficiary, recommended by a pharmacist or prescribed during a doctor's consultation for treatment of a minor illness. In South Africa private health insurance is provided by not-for-profit medical aid schemes. In 2015 there were 87 medical aid schemes registered with the Council for Medical Schemes (CMS), the Government regulatory body. ${ }^{8}$ Each one offers access to a range of medical, dental, optical, paramedical and medicinal services known as "benefits." Benefit combinations vary between medical aid schemes, with each combination termed a "plan" or "option". Health plans are purchased by "beneficiaries" on the basis of affordability and healthcare needs. Where healthcare is accessed within the public sector which serves more than $80 \%$ of the population, S1, S2 medicines are prescribed and dispensed according to the South African Essential Medicines List (EML) which is a formulary with a limited number of OTC medicines, typically only includes single-compound products and does not include combination medicines. ${ }^{9}$

An additional issue with OTC medicines is that the combination and concentration/strength of ingredients may be identical or differ only marginally between products, yet prices vary markedly without sound basis. However, it is not only the varying cost of the products themselves, but also the potential costs of their adverse effects that are important. For example, a study by Friedman showed that cheaper, "old generation" sedating antihistamines were easily accessible for allergic conditions, but the longterm cost impact of the adverse effects of these drugs had not been considered. ${ }^{10}$ In terms of potential costs of adverse outcomes, the codeine-containing medicines represent a category that raises or should raise concerns in the country. As a result of legislation, OTC medicines are restricted to $10 \mathrm{mg}$ of codeine per dose. ${ }^{7}$ While this is restrictive, it does not limit the risk of addiction. ${ }^{11}$ Codeine abuse is currently receiving attention globally, with Australia removing codeine-containing OTC preparations and "up-scheduling" them to the "prescription only" category, ${ }^{12}$ while measures to restrict access are also being considered in the United States and Canada. ${ }^{13,14}$

Council for Medical Schemes annual reports indicate that a high percentage of covered beneficiaries access the OTC benefit, irrespective of whether they have restricted or generous benefits. ${ }^{8}$ Furthermore, as shown by others, it appears that the higher the available benefit, the more tends to be spent on an event, despite the fact that spending more-carefully would extend the value of the benefit. ${ }^{15}$ Medical aid schemes provide little in the way of member education and also have few, if any, cost-containment initiatives within the OTC benefit. ${ }^{8}$ This may be because schemes have limited interest in how the benefit is used. It is typically capped in one way or another and structured in such a way that it functions as a debit card account, to be used at the discretion (or indiscretion) of the beneficiary concerned.

Access to care, cost of care and quality are key elements in any discussion around a health system. The aim of the present study is to investigate the utilization patterns in two South African medical aid schemes of a high-impact set of OTC products. As such the focus was on analgesic products in the Anatomical Therapeutic Chemical (ATC) N02BE51 category which includes medicines containing paracetamol and varying combinations of codeine, caffeine and antihistamines. The study addresses individual products and explores costs, volumes and elements of quality, the latter mainly related to regulatory oversight of pricing and formulation of products in the ATC category under review. We also discuss findings in relation to the current national debate around costs in the private sector in general, and the intended transition to universal, affordable access to quality healthcare. 


\section{Methodology}

Beneficiaries were selected from a 2015 database provided by a large medical aid scheme administration company in South Africa. Administration companies take on the dayto-day operational activities of one or more medical aid schemes. Services range from enrolment of members to payment of claims, actuarial services and production of management reports. The administrator who provided our data has been in existence for over 40 years and serves more than 3 million lives within a number of medical aid schemes. The various medical aid schemes, their specific benefit options/plans and beneficiaries were not identifiable; as such all data were confidential. One year's data was provided for analysis covering 12 plans with 641525 beneficiaries in total. Only two plans were selected for this study, one within a high benefit medical aid scheme with a comprehensive set of generous benefits (designated $\mathrm{HI}$ ), the other offering a lower benefit plan (designated LO). In both plans there was access to OTC medicines up to specified limits.

Beneficiaries were identified only by a unique study number. Background information provided for each beneficiary included gender, age and ethnicity. Medicines data extracted included only S1,S2 medicines. Those prescribed or dispensed by a doctor are referred to as doctor-prescribed (DP) medicines, while those accessed directly by the beneficiary or on the recommendation of the pharmacist are referred to as beneficiary/pharmacist (BP) medicines. In the South African context all medically-qualified and registered practitioners are referred to as doctors, whether general practitioners, specialists or sub-specialists in the various medical and surgical disciplines.

Actual indication for the medicines could not be ascertained because of the frequent use of a non-specific diagnostic ICD10 code such as in the Z76 category which covers "Persons encountering health services in unspecified circumstances." ${ }^{16}$ Each medicine claimed was coded according to its ATC classification. ${ }^{17}$ Within the ATC system medicines are grouped into five levels (anatomical main group, therapeutic subgroup, pharmacological subgroup, chemical subgroup and chemical substance). One of the most-frequently accessed categories, N02BE51, covers $\mathrm{N}$ : the nervous system, 02 represents analgesics, $\mathrm{BE}$ and 51 cover paracetamol and its combination with various ingredients, excluding psycholeptics. In South Africa this ATC category includes a large number of products, most of which have varying combinations of a relatively limited number of ingredients. Products may be original or generic and be priced very differently, in many cases for identical formulations. ${ }^{18}$

This ATC category was selected not only because its overall utilization was high in both HI and LO plans, but also because of the potential for products in this category to present with adverse drug reactions. ${ }^{19}$ For both $\mathrm{HI}$ and LO plans the top 10 N02BE51 products were selected based on volume, whether accessed via the DP or BP route. The contribution of each product to the total cost within the ATC was calculated, together with the average cost of each product as submitted to and paid by the medical aid scheme. To establish whether the HI and LO plans selected for this study were representative of utilization in other plans, five other plans were randomly selected from the database of 12 plans. A correlation analysis was performed for the top products of the five against the products accessed within the two plans used in this study. Results showed correlation coefficients that ranged between 0.84 and 0.99 , with $p$-values ranging from $<0.005$ to 0.000 . Statistical analysis was carried out using Statistica (Version 13.2 TIBCO Software Inc., Palo Alto, CA, USA) which was also used for descriptive statistics and frequency analysis. Significance was set at $p<0.05$.

In the DP option in both plans, the top 10 medicines by volume were further separated, based on whether they were prescribed by a formally-registered dispensing doctor (who stocks medicines within her/his practice) or a nondispensing doctor (who writes a prescription for dispensing by a pharmacist). An additional level of service provision and DP-prescribing explored the involvement of contracted, preferred/designated service providers (DSPs), alternatively referred to as "network doctors" This applied only to the LO plan as it was not a managed care strategy employed by the HI plan.

Ethics approval was obtained from the Human Ethics Committee of the University of the Witwatersrand (certificate M160141).

\section{Results}

Table 1 shows the ranking of 14 branded products in the NO2BE51 ATC by composition and volume in the HI plan, whether BP-dispensed or DP-prescribed. Six products were common to both DP and BP. The generic use within both DP and BP categories was similar. Of the top 10 in both BP and DP categories, seven of the products have the same chemical composition, yet prices ranged between R7.54 and 
Table I Top 10 branded products coded by contents and ranked by volume in the N02BE5I ATC for BP and DP (HI plan)

\begin{tabular}{|c|c|c|c|c|c|}
\hline BP & $\begin{array}{l}\text { Number of } \\
\text { claims }\end{array}$ & Avg cost per product (Rand) & DP & $\begin{array}{l}\text { Number of } \\
\text { claims }\end{array}$ & Avg cost per product (Rand) \\
\hline Al & 688 & 66.86 & $\mathrm{Al}$ & 146 & 46.24 \\
\hline A2 & 287 & 96.33 & B2 & 83 & 25.02 \\
\hline $\mathrm{A} 3 *$ & 146 & 110.08 & $\mathrm{~A} 2$ & 67 & 90.81 \\
\hline BI & 60 & 42.17 & $\mathrm{EI} *$ & 36 & 16.59 \\
\hline A4 & 57 & 79.74 & A6 & 31 & 7.54 \\
\hline B2 & 57 & 24.12 & $\mathrm{~A} 3^{*}$ & 28 & 90.71 \\
\hline A5 & 50 & 38.95 & A4 & 27 & 80.53 \\
\hline $\mathrm{Cl}$ & 41 & 114.46 & A7 & 27 & 54.47 \\
\hline DI & 31 & 48.52 & D2 & 24 & 25.12 \\
\hline $\mathrm{EI} *$ & 30 & 47.45 & B3 & 22 & 10.26 \\
\hline \multicolumn{3}{|c|}{ Total spend in category N02BE5I: RII7 580} & \multicolumn{3}{|c|}{ Total spend in category N02BE5I: R29 946} \\
\hline \multicolumn{3}{|c|}{ Top 10 spend in N02BE5 I: RI07 737 (91.63\%) } & \multicolumn{3}{|c|}{ Top 10 spend in N02BE5I: R22 756 (76.0\%) } \\
\hline \multicolumn{3}{|c|}{ Average cost of top 10: R66.87 } & \multicolumn{3}{|c|}{ Average cost of top 10: R44.73 } \\
\hline \multicolumn{3}{|c|}{ \% volume of generics: 87.84} & \multicolumn{3}{|c|}{ \% volume of generics: 86.97} \\
\hline
\end{tabular}

Notes: *Original; ${ }^{\mathrm{Al}-\mathrm{A} 7}$ Paracetamol, codeine, caffeine and doxylamine tablets. ${ }^{\mathrm{BI}-\mathrm{B} 3}$ Paracetamol, codeine and promethazine syrup. ${ }^{\mathrm{Cl}}$ Paracetamol, codeine, caffeine and diphenhydramine tablets. ${ }^{\mathrm{DI}-\mathrm{D} 2}$ Tripolidine, pseudoephedrine and paracetamol syrup. ${ }^{\mathrm{EI}}$ Codeine, caffeine and phenyltoloxamine tablets Abrreviations: BP, beneficiary/pharmacist accessed; DP, doctor prescribed; HI, high benefits.

R110. The average cost for the top 10 in the BP category was R66.82 in contrast to R44.73 in the DP category.

Table 2 shows volume and cost comparisons for identical products prescribed by non-dispensing and dispensing doctors. When comparing identical products dispensed by the two doctor groups it is clear that the dispensing doctors showed better cost containment. For the non-dispensing doctors the medicine costs were almost twice as high as those of the dispensing doctors. Two products (A1,A2) have similar ingredients but costs ranged between R28.08 and R109.96. Some of the large price differences could be the result of differing pack sizes. This is explored below (Table 3).

Table 3 compares the frequency with which smaller and larger pack sizes of the two most commonly utilised products (A1, A2) were dispensed between three groups: dispensing doctors, non-dispensing doctors and pharmacists. Frequency

Table 2 Cost comparisons for identical Top 10 products prescribed by dispensing vs non-dispensing doctors in ATC N02BE5I in HI plan

\begin{tabular}{|l|l|l|l|}
\hline $\begin{array}{l}\text { Non-dispen- } \\
\text { sing Dr }\end{array}$ & $\begin{array}{l}\text { Avg cost } \\
\text { (Rand) }\end{array}$ & $\begin{array}{l}\text { Dispensing } \\
\text { Dr }\end{array}$ & $\begin{array}{l}\text { Avg cost } \\
\text { (Rand) }\end{array}$ \\
\hline Al & 60.03 & Al & 28.08 \\
B2 & 27.61 & B2 & 13.28 \\
A2 & 109.96 & A2 & 34.48 \\
EI* & 23.77 & $\mathrm{EI}^{*}$ & 12.02 \\
\hline
\end{tabular}

Notes: *Original; ${ }^{\mathrm{Al}-\mathrm{A} 2}$ Paracetamol, codeine, caffeine and doxylamine tablets. ${ }^{\mathrm{B} 2}$ Paracetamol, codeine and promethazine syrup. ${ }^{\mathrm{EI}}$ Codeine, caffeine and phenyltoloxamine tablets.

Abrreviations: ATC, Anatomical Therapeutic Chemical; HI, high benefits. analysis showed that there was significantly more dispensing of large packs by pharmacists, while dispensing doctors were significantly less inclined to do so. This had an impact on costs reflected in Tables 1 and 2.

Table 4 shows the ranking of 15 branded products by composition and volume in the N02BE51 ATC in the LO plan. Five products were common to both DP and BP categories, with almost complete use of generics in both. Eight products contain similar ingredients. The average product price in the BP category was more than double

Table 3 Pack sizes for two commonly- utilised products according to service provider in $\mathrm{HI}$ plan

\begin{tabular}{|l|l|l|}
\hline HI Plan & $\begin{array}{l}\text { Al } \\
\text { Number of packs } \\
\text { dispensed }\end{array}$ & $\begin{array}{l}\text { A2 } \\
\text { Number of packs } \\
\text { dispensed }\end{array}$ \\
\hline $\begin{array}{l}\text { Non-dispensing Dr } \\
\text { Dispensing Dr } \\
\begin{array}{l}\text { Pharmacist dis- } \\
\text { pensed (OTC) }\end{array}\end{array}$ & $\begin{array}{l}24^{*} \\
219^{*}\end{array}$ & Pack Size 18 \\
\hline $\begin{array}{l}\text { Pack 20 } \\
\text { Dispensing Dr } \\
\text { Pharmacist dis- } \\
\text { pensed (OTC) }\end{array}$ & $\begin{array}{l}8^{*} \\
428^{*}\end{array}$ & 162 \\
\hline
\end{tabular}

Notes: ${ }^{\mathrm{Al}-\mathrm{A} 2}$ Paracetamol, codeine, caffeine and doxylamine tablets. *Chi-square for comparison of dispensing of pack sizes by different providers: $p<0.001$.

Abrreviations: OTC, over-the-counter; HI, high benefits. 
Table 4 Top 10 branded products coded by contents and ranked by volume in the N02BE5I ATC for BP and DP (LO Plan)

\begin{tabular}{|c|c|c|c|c|c|}
\hline $\mathbf{B P}$ & Number of claims & Avg cost per Product (Rand) & DP & $\begin{array}{l}\text { Number of } \\
\text { claims }\end{array}$ & Avg cost per Product (Rand) \\
\hline Al & 4632 & 49.74 & B2 & 1302 & 16.47 \\
\hline $\mathrm{A} 2$ & 1256 & 68.25 & Al & 1109 & 26.03 \\
\hline B2 & 1037 & 17.36 & D2 & 943 & 21.35 \\
\hline D3 & 854 & 18.96 & B3 & 840 & 10.26 \\
\hline D2 & 547 & 23.44 & D3 & 685 & 17.64 \\
\hline A8 & 537 & 38.57 & B4 & 559 & 13.58 \\
\hline A5 & 505 & 38.98 & B5 & 420 & 17.08 \\
\hline A4 & 432 & 57.67 & $\mathrm{~A} 2$ & 411 & 45.08 \\
\hline DI & 416 & 39.82 & A9 & 374 & $15.0 \mid$ \\
\hline $\mathrm{A}^{*} *$ & 357 & 71.50 & A6 & 312 & 9.45 \\
\hline \multicolumn{3}{|c|}{ Total spend in category N02BE5 I: R522 199} & \multicolumn{3}{|c|}{ Total spend in category N02BE5I: RI93867 } \\
\hline \multicolumn{3}{|c|}{ Top 10 spend in N02BE5I: R475 023 (90.97\%) } & \multicolumn{3}{|c|}{ Top I0 spend in N02BE5I: RI32 988 (68.60\%) } \\
\hline \multicolumn{3}{|c|}{ Average cost of top 10: R42.43 } & \multicolumn{3}{|c|}{ Average cost of top 10: R19.19 } \\
\hline \multicolumn{3}{|c|}{ \% volume of generics: 96.62} & \multicolumn{3}{|c|}{$\%$ volume of generics: 100} \\
\hline
\end{tabular}

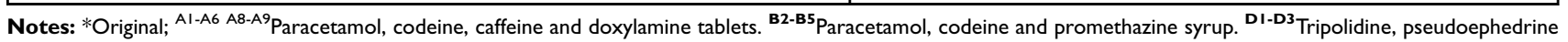
and paracetamol syrup.

Abbreviations: ATC, Anatomical Therapeutic Chemical; BP, beneficiary/pharmacist accessed; DP, doctor prescribed; LO, low benefits.

that of the DP category (R42.43 vs R19.19). The use of smaller pack sizes is detailed below (Table 6), but the choice of cheaper generics by doctors and proportionally lower dispensing fees may also have distorted the average cost in favour of the doctors.

Table 5 shows the cost differences for products common to both non-dispensing and dispensing doctors. For four of the six common products the costs were very close, however once again for the two generics that contain paracetamol, caffeine, doxylamine and codeine there was a substantial difference. This is shown below as a possible manifestation of pack size differences (Table 6).

Table 6 shows frequency of dispensing by dispensing doctors, non-dispensing doctors and pharmacists. In comparison with the HI plan there appeared to be more

Table 5 Cost comparisons for identical Top 10 products prescribed by dispensing vs non-dispensing doctors in ATC N02BE5I in LO

\begin{tabular}{|l|l|l|l|}
\hline Non-dispensing Dr & $\begin{array}{l}\text { Avg cost } \\
\text { (Rand) }\end{array}$ & Dispensing Dr & $\begin{array}{l}\text { Avg cost } \\
\text { (Rand) }\end{array}$ \\
\hline A1 & 37.04 & A1 & 17.37 \\
A2 & 60.48 & A2 & 33.20 \\
B2 & 17.68 & B2 & 14.63 \\
B5 & 19.73 & B5 & 16.44 \\
D2 & 23.87 & D2 & 20.65 \\
D3 & 19.18 & D3 & 17.16 \\
\hline
\end{tabular}

Notes: Al-A2 Paracetamol, codeine, caffeine and doxylamine tablets. ${ }^{\text {BI-B2. }}$

${ }^{\mathrm{B} 5}$ Paracetamol, codeine and promethazine syrup. ${ }^{\mathrm{D} 2-\mathrm{D} 3}$ Tripolidine, pseudoephedrine and paracetamol syrup.

Abbreviations: ATC, Anatomical Therapeutic Chemical; LO, low benefits. "balanced" use of smaller and larger pack sizes, but frequency analysis showed again that pharmacists, and to an extent non-dispensing doctors, resorted to larger pack sizes than dispensing doctors. There was an impact of pack size dispensing on costs as reflected in Tables 4 and 5.

Table 7 shows costs attributable to different doctor categories. Network doctors are doctors who have service-level and payment agreements with medical aid schemes. These doctors were further categorised as either dispensing or non-dispensing doctors. There was not much

Table 6 Pack sizes for two commonly- utilised products according to service provider in LO plan

\begin{tabular}{|c|c|c|}
\hline LO & $\begin{array}{l}\text { Al } \\
\text { Number of packs } \\
\text { dispensed }\end{array}$ & $\begin{array}{l}\text { A2 } \\
\text { Number of packs } \\
\text { dispensed }\end{array}$ \\
\hline & Pack size 20 & Pack size 18 \\
\hline \multirow{4}{*}{$\begin{array}{l}\text { Non-dispensing Dr } \\
\text { Dispensing Dr } \\
\text { Pharmacist dispen- } \\
\text { sing (OTC) }\end{array}$} & $265^{*}$ & 91 \\
\hline & $448 *$ & 116 \\
\hline & $2097^{*}$ & 774 \\
\hline & Pack Size 100 & Pack size 100 \\
\hline Non-dispensing Dr & $126 *$ & 27 \\
\hline Dispensing Dr & $I^{*}$ & 0 \\
\hline $\begin{array}{l}\text { Pharmacist dis- } \\
\text { pensed (OTC) }\end{array}$ & $2214^{*}$ & 302 \\
\hline
\end{tabular}

Notes: ${ }^{\mathrm{Al}-\mathrm{A} 2}$ Paracetamol, codeine, caffeine and doxylamine tablets. ${ }^{*}$ Chi-square for comparison of dispensing of pack sizes by different providers: $p<0.001$.

Abrreviations: OTC, over-the-counter; LO, low benefits. 
Table 7 Cost comparisons for identical products provided by network doctor vs non-network doctors in the non-dispensing and dispensing doctor categories

\begin{tabular}{|c|c|c|c|}
\hline $\begin{array}{l}\text { Non-dispensing } \\
\text { Dr }\end{array}$ & $\begin{array}{l}\text { Avg cost } \\
\text { (Rand) }\end{array}$ & Dispensing Dr & $\begin{array}{l}\text { Avg cost } \\
\text { (Rand) }\end{array}$ \\
\hline \multicolumn{2}{|l|}{ Al } & \multicolumn{2}{|l|}{ Al } \\
\hline Network Dr & 35.74 & Network Dr & 17.47 \\
\hline Non-network Dr & 45.56 & Non-network Dr & 14.19 \\
\hline \multicolumn{2}{|l|}{ A2 } & \multicolumn{2}{|l|}{$\mathrm{A} 2$} \\
\hline Network Dr & 58.75 & Network Dr & 16.44 \\
\hline Non-network Dr & 70.66 & Non-network Dr & 20.56 \\
\hline \multicolumn{2}{|l|}{ B2 } & \multicolumn{2}{|l|}{ B2 } \\
\hline Network Dr & 17.49 & Network Dr & 33.20 \\
\hline Non-Network & 18.63 & Non-network Dr & 30.01 \\
\hline Dr & & & \\
\hline \multicolumn{2}{|l|}{ B5 } & \multicolumn{2}{|l|}{ B5 } \\
\hline Network Dr & 19.64 & Network Dr & 17.16 \\
\hline Non-network Dr & 20.23 & Non-network Dr & 15.20 \\
\hline \multicolumn{2}{|l|}{ D2 } & \multicolumn{2}{|l|}{ D2 } \\
\hline Network Dr & 23.72 & Network Dr & 14.66 \\
\hline Non-network Dr & 25.04 & Non-network Dr & 13.42 \\
\hline \multicolumn{2}{|l|}{ D3 } & \multicolumn{2}{|l|}{ D3 } \\
\hline Network Dr & 19.37 & Network Dr & 20.65 \\
\hline Non-network Dr & 18.00 & Non-network Dr & 20.67 \\
\hline $\begin{array}{l}\text { Average cost } \\
\text { (All products) }\end{array}$ & 31.06 & $\begin{array}{l}\text { Average cost } \\
\text { (All products) }\end{array}$ & 19.47 \\
\hline
\end{tabular}

Notes: ${ }^{A 1-A 2}$ Paracetamol, codeine, caffeine and doxylamine tablets. ${ }^{\mathbf{B 2}}$, ${ }^{\text {B5 }}$ Paracetamol, codeine and promethazine syrup. ${ }^{\text {D2, D3 }}$ Tripolidine, pseudoephedrine and paracetamol syrup.

difference in costs between network and non-network doctors, irrespective of whether they dispensed directly to patients or wrote prescriptions for dispensing by a pharmacy. However, as shown in previous Tables, the average cost remained higher for the non-dispensing doctors compared to the dispensing doctors (R31.06 vs R19.47).

\section{Discussion}

This study focused on 14 branded products in the N02BE51 ATC category representing 'top 10' expenditure in the HI plan and 15 products in the LO plan. Overall, 50 mostly-paracetamol-based and codeine-containing products were dispensed in the NO2BE51 category, with variable prices but limited differences in terms of their composition. South Africa has "single exit price" legislation that compels all manufacturers to declare the price of each product and seeks to ensure that prices are not inflated at points of sale. ${ }^{20}$ However, as shown in this study, there is no requirement for manufacturers to justify prices or show how they were derived. This results in identically-formulated products having markedly differences prices. This aspect is confirmed and covered in detail in a recent report which showed that twothirds of 6613 products across the ATC categories were formulated identically to one or more others. ${ }^{18}$ The use of several generic products in this study raises the question of whether similarly-constituted products are always and reliably clinically equivalent. This is an important issue that has been reviewed by others who note that particularly in emerging economies and developing countries there is variability between drug batches, between generic and originator products, and impurities may be present. ${ }^{21}$

The cost differentials for identical products according to how they are accessed also indicates that legislation that is intended to regulate dispensing fees and the handling costs of medicines is also failing. ${ }^{22}$ Costs to the medical aid schemes were related to the available benefits; the higher the available benefit the greater the cost even for identical products. This is in accordance with published data. ${ }^{15}$

The cost of OTC products accessed by beneficiaries or recommended by pharmacists was higher than when prescribed by a doctor. This has been reported for Schedule 0 medicines in South Africa but to our knowledge has not been studied for $\mathrm{S} 1$ and $\mathrm{S} 2$ OTC medicines. ${ }^{23}$ Furthermore, non-dispensing doctors appeared to be more cost-effective than dispensing doctors, and network contracts between the medical aid schemes and doctors did not appear to generate OTC medicines savings. These findings accord with other local research. ${ }^{24,25}$

In some cases the cost differentials appeared to be related to provision of larger pack sizes by pharmacists and non-dispensing doctors (whose prescriptions are ultimately dispensed by pharmacists). Further investigation is required to assess the extent to which dispensed quantities might differ from what was prescribed. In this regard recent changes to legislation ${ }^{5}$ prevent the sale of large pack sizes, but this does not necessarily prevent pharmacists from dispensing multiple boxes of a smaller quantity. It is possible/likely that pharmacies have higher overhead costs than dispensing doctors, and that they dispense accordingly in order to maximise returns. While regulated by government, ${ }^{22}$ the variable application of dispensing fees may be a factor in the cost differentials. This was not measurable in this study. 
Several ingredients within the S1,S2 category, for example ephedrine, pseudoephedrine and codeine are subject to legislative restrictions. ${ }^{6,7}$ In the ATC category under review, codeine is included in several products up to the specified maximum concentration. While codeine is a weak opioid, despite these safeguards the drug has the potential for abuse and dependence. Furthermore, sedation, and euphoria are common side effects that may impair function. ${ }^{26}$ Simply decreasing the codeine quantity accessible to an individual consumer is also not an effective control because in the medical aid schemes environment it is possible for one beneficiary to access additional OTC quantities by simply using another family member's benefit. In fact, research has shown that in this country $43 \%$ of codeine abusers accessed codeine-containing products through their medical aid schemes. ${ }^{27}$ A recent investigative report has also highlighted poor oversight by government and poor compliance in the dispensing of codeine-containing products by pharmacists. ${ }^{28}$

Billions are spent annually on OTCs in South Africa, apparently not in a cost-effective manner. It is therefore appropriate to consider whether free market principles should prevail or interventions introduced that would better regulate access to and the cost and quality of OTCs. For the BP category, in order to reduce costs medical aid schemes could enhance managed care interventions, perhaps restrict access to lower cost products by following strategies such as the Maximum Medical Aid Price $(\text { MMAP) })^{29}$ or a medical aid scheme-specific recommended price list that would only cover products at the lower end of the cost spectrum. ${ }^{30}$ Medical aid schemes could also do more to develop evidence-based OTC formularies and educate beneficiaries in the use thereof. Benefits could be restructured in order to create greater awareness of cost implications, although research has shown that "brand awareness" does not change in response to such initiatives. ${ }^{31}$ Alternatively, the benefit could be abolished completely, leaving beneficiaries to self-medicate according to affordability, but in this regard research has shown that while "price shopping" may be supported in theory, consumers are limited in their ability to effect change. ${ }^{32}$ In the DP category, medical aid schemes could pay more attention to the potential value of doctors, predominantly general practitioners but dispensing doctors in particular, who appear to be more aware of costs in their prescribing of OTCs to patients.

To a large extent managed care initiatives are in effect in the public sector through processes such as the State's tender system (which manages the cost aspect) and formularies such as the EML (which restricts access to a limited range of products and also affects quality by excluding most multi-ingredient products). ${ }^{9}$ Extension of State control to the private sector's access to OTC medicines would almost certainly impact on overall costs and quality through regulation in areas of pricing, product composition and polypharmacy. On the other hand, up-scheduling of an ingredient such as codeine would likely lead to an increase in costs through additional consultations with doctors and also financial disadvantage to pharmacies. ${ }^{33}$

The results of this analysis and the list of possible interventions should also be considered within the context of current debates around private sector healthcare in South Africa. Three documents are under consideration: the National Health Insurance (NHI) Bill, the interim report of the Health Market Inquiry (HMI), and the Medical Schemes Amendment (MSA) Bill. ${ }^{34-36}$ The NHI Bill is focused on the future, while the HMI report is directed towards the existing private healthcare system with an emphasis on the roles of private hospitals, medical aid schemes, administrators and doctors in driving the costs of private healthcare. Pharmaceutical companies, manufacturers and distributors of OTCs were not covered by the HMI, but recommendations in the interim report certainly apply and are consistent with the interventions proposed above based on results of the present study. These include the need to introduce value-based purchasing, effectively control costs, educate disempowered and uninformed medical aid scheme beneficiaries, and use DSPs with obligations to provide cost-effective quality healthcare.

The proposed amendments to the Medical Schemes Act include ten major changes of which two are particularly relevant to this study: revising the current acute benefit package to include primary health care (PHC) medicines and care, and ensuring that the comprehensive benefit package is covered in full without co-payments. In terms of OTCs, if the amendments become law then in future the medical aid schemes would likely include within the PHC benefit the common ATC categories and the polypharmaceuticals discussed in this paper. According to the NHI Bill these would then have to be covered in full with no co-payments. Without attention being given to access and cost controls, the lack of formularies, DSPs, networks and guaranteed prices, there is thus a risk that the proposed MSA amendments would actually result in higher expenditure on OTCs in the future. 


\section{Conclusion}

Within the medical aid schemes industry, access to and costs of OTC medicines are poorly managed, whether by the beneficiaries, medical aid schemes/administrators, pharmacists or State. On the positive side, doctors (particularly doctors who dispense from their consulting rooms) show better cost containment compared to pharmacists, who appeared to favour more-expensive products in larger pack sizes. The recommendations emanating from this study are consistent with those that appeared in the recent interim report of the Health Market Inquiry, ${ }^{35}$ demonstrating that cost drivers that apply to hospitals, administrators and doctors apply similarly in the OTC market, with stakeholders endeavouring to drive costs up rather than down.

\section{Disclosure}

The authors have no conflicts of interest in this work.

\section{References}

1. Healthcare and Lifesciences Review. 2016. Available from: https:// pharmaboardroom.com/pharmareport/south-africa-pharma-report. Accessed September 26, 2018

2. Concern over rising medicine prices in SA as Adcock Ingram profit soars. 2018 Available from: https://businesstech.co.za/news/business/ 267957/concern-over-rising-medicine-prices-in-sa-as-adcock-ingramprofit-soars. Accessed November 12, 2018.

3. Markotic F, Jurisic D, Curkovic M, et al. Sharing of prescription analgesics amongst patients in family practice: frequency and associated factors. Eur J Pain. 2018;22(4):716-727. doi:10.1002/ejp.1157

4. South African Health Products Regulatory Authority. Scheduling of Medicines. Available from: https:/www.sahpra.org.za/documents/ a56714ff2.36_Scheduling_of_Medicines_Jun14_v1.pdf. Accessed September 26, 2018.

5. Gray A, Vawda Y. Health Policy and Legislation. Padarath A, Barron P editors. South African Health Review 2017. Durban: Health Systems Trust; 2017: 52. Available from: http://www.hst.org.za/pub lications/South\%20African\%20Health\%20Reviews/HST\%20SAHR \%202017\%20Web\%20Version.pdf. Accessed 27 September, 2018.

6. South African Health Products Regulatory Authority. Medicines and Related Substances Act, 1965 (Act 101 of 1965) Schedules. Available from: http://www.sahpra.org.za/documents/ca12c1aeGov_Gazette_ 31010_25April2008_Scheduling_of_pseudoephedrine_BZP.pdf. Accessed September 26, 2018

7. South African Health Products Regulatory Authority. Consolidated Schedules. Available from: https:/www.sahpra.org.za/documents/ f6bf8a532016_Consolidatedschedules2008200920112012201 320142015March_May2016(includingprescribers).pdf. Accessed September 26, 2018

8. Council of Medical Schemes. Available from: https://www.medi calschemes.com. Accessed April 29, 2019

9. Standard treatment guidelines and Essential Medicines List for South Africa. 2013. Available from: http://www.kznhealth.gov.za/phar macy/PaedsSTG2013LR.pdf. Accessed September 26, 2018.

10. Friedman RL. Allergic rhinitis prescription - where to now in South Africa? Current Allergy Clin Immunol. 2006;4(19):180-185.
11. Carney T, Wells J, Parry CD, McGuinness P, Harris R, Van Hout MC. A comparative analysis of pharmacists' perspectives on codeine use and misuse - a three-country survey. Subst Abuse Treat Prev Policy. 2018;13(1):12. doi:10.1186/s13011-018-0149-2

12. McCoy J, Bruno R, Nielsen S. Attitudes in Australia on the upscheduling of over-the-counter codeine to a prescription-only medication. Drug Alcohol Rev. 2018;37(2):257-261. doi:10.1111/dar.12568

13. ABC News. Available from: https://www.abc.net.au/radionational/pro grams/breakfast/canada-moves-to-ban-over-the-counter-codeinesales/9364194 Accessed April 28, 2019

14. US Food and Drug Administration. Available from: https://www.fda. gov/drugs/drug-safety-and-availability/fda-drug-safety-communica tion-fda-restricts-use-prescription-codeine-pain-and-cough-medi cines-and Accessed April 28, 2019

15. Otto M, Armeni P, Jommi C. Variations in non-prescription drug consumption and expenditure: determinants and policy implications. Health Policy. 2018;122(6):614-620. doi:10.1016/j.healthpol.2018.01.012

16. ICD-10. Available from: www.icd10data.com/ICD10CM/CodesZ00Z99 Accessed May 2, 2019

17. World Health Organisation. The Anatomical Therapeutic Chemical Classification System with defined daily doses Available from: http:// www.who.int/classifications/atcddd/en. Accessed November 12, 2018

18. The Supply of Pharmaceuticals in South Africa. Helen Suzman Foundation. 2018. Available from: https://hsf.org.za/publications/spe cial-publications/pharmaceuticals-in-south-africa/pharma-report2018.pdf Accessed November 12, 2018

19. Schmiedl S, Rottenkolber M, Hasford J, et al. Self-medication with overthe-counter and prescribed drugs causing adverse-drug-reaction-related hospital admissions: results of a prospective, long-term multi-centre study. Drug Saf. 2014;37:225-235. doi:10.1007/s40264-014-0141-3

20. Single Exit Pricing. Department of Health. Available from: http:// www.health.gov.za/index.php/2014-03-17-09-09-38/legislation/ joomla-split-menu/category/121-reg2004. Accessed April 29, 2019

21. Johnston A, Holt DW. Substandard drugs: a potential crisis for public health. Br J Clin Pharmacol. 2014;78(2):218-243. doi:10.1111/bcp.12298

22. Dispensing Fee. Available from: https://www.gov.za/sites/default/ files/gcis_document/201409/326851053.pdf. Accessed June 6, 2019.

23. Perumal-Pillay VA, Thereshen Reddy SF. An exploratory study into the use of pricing of schedule zero medicines post exemption from the single exit price policy in South Africa. Global $J$ of Health Sc. 2019;11(3):23-31. doi:10.5539/gjhs.v11n3p23

24. Trap B, Hansen EH, Hogerzeil HV. Prescription habits of dispensing and non-dispensing doctors in Zimbabwe. Health Pol and Plan. 2002;17(3):288-295. doi:10.1093/heapol/17.3.288

25. Modi $\mathrm{BH}$ The comparative cost of treating medical aid and nonmedical aid patients attending private general practitioners. Master of Medicine Dissertation, 2013. University of the Witwatersrand, Johannesburg.

26. Nielsen S, Van Hout MC. Over-the-counter codeine -from therapeutic use to dependence, and the grey areas in between. Curr Top Behav Neurosci. 2016;34:59-75.

27. Dada S, Burnhams NH, Van Hout MC, Parry CDH. Codeine misuse and dependence in South Africa- learning from substance abuse treatment admissions. South Afr Med J. 2015;105(9):776-779. doi:10.7196/SAMJnew.8172

28. Carte Blanche Investigation, M-net DSTV. Available from: https://mnet.dstv.com/show/carte-blanche/news/codeine-addictions-signs-andsymptoms-carte-blanche/news Accessed November 11, 2018

29. Boyce D, Bartlett G. The maximum medical aid price programme: A review of the concept and of its ability to reduce expenditure on medicines. South Afr Med J. 1990;78(8):147-151.

30. Rothberg AD, Blignault J, Serfontein CB, et al. Experience of a medicines reference-pricing model. South Afr Med J. 2004;94 (3):183-188. 
31. Parente ST, Feldman R, Chen S. Effects of a consumer driven health plan on pharmaceutical spending and utilisation. Health Serv Res. 2008;43(5p1):1542-1556. doi:10.1111/j.1475-6773.2008.00857.x

32. Semigran HL, Gourevitch R, Sinaiko AD, Cowling D, Mehrotra A. Patients' views on price shopping and price transparency. Am J Manag Care. 2017;23(6):e186-e192.

33. Gudin J, Lee AJ. The downside of upscheduling. Pain Med. 2013;14 (11):1628-1629. doi:10.1111/pme.12257_3

34. National Health Insurance Bill. 2018. Available from: http://www. health.gov.za/index.php/gf-tb-program/398-national-health-insur ance-bill-2018. Accessed November 12, 2018.
35. Health Market Inquiry: Provisional findings and recommendations. 2018. Available from: http://www.compcom.co.za/wp-content/ uploads/2018/07/Health-Market-Inquiry-1.pdf. Accessed November $12,2018$.

36. Medical Schemes Amendment Bill. 2018. Available from: https://www. gov.za/sites/default/files/41726_gon636s.pdf Accessed November 12, 2018

\section{Publish your work in this journal}

Drug, Healthcare and Patient Safety is an international, peer-reviewed open-access journal exploring patient safety issues in the healthcare continuum from diagnostic and screening interventions through to treatment, drug therapy and surgery. The journal is characterized by the rapid reporting of reviews, original research, clinical, epidemiological and post-marketing surveillance studies, risk management, health literacy and educational programs across all areas of healthcare delivery. The manuscript management system is completely online and includes a very quick and fair peer-review system. Visit http://www.dovepress.com/testimonials.php to read real quotes from published authors. 